\title{
Analisis Dosis Serap Organ Kritis Lensa Mata Pada Terapi Karsinoma Nasofaring Dengan Pesawat LINAC 6 MV
}

\author{
Dewiana $^{1}$, Agung Nugroho Oktavianto ${ }^{1}$, Ari Mutanto ${ }^{1}$ \\ ${ }^{1}$ Program Studi Fisika, Fakultas Teknik dan Sains, Universitas Nasional, Jakarta \\ Email: arimutanto.mutanto694@gmail.com
}

\begin{abstract}
ABSTRAK. Karsinoma Nasofaring merupakan kanker ganas yang berasal dari tubuh yang secara anatomi berbatas tegas, yaitu pada daerah nasofaring. Organ kritis/organ sehat yang terdekat dan masuk di dalam lapangan penyinaran adalah mata, dimana lensa mata mempunyai dosis toleransi 500 cGy pada $5 / 5$ (peluang komplikasi yang tidak lebih dari $5 \%$ dalam waktu 5 tahun). ${ }^{[2]}$ Salah satu penanganan karsinoma nasofaring adalah dengan pesawat linear accelerator $6 \mathrm{MV}$ yang dilengkapi dengan Multi Leaf Colimator. Metode yang digunakan adalah dengan metode 3 lapangan penyinaran (2 latero lateral dan 1 antero posterior). Adapun penelitian ini menggunakan TLD sebanyak 14 butir yang ditempatkan pada permukaan lensa mata kanan dan lensa mata kiri masing-masing 7 butir di lensa mata kanan dan 7 butir dilensa mata kiri, dengan 3 kali penyinaran per fraksi $200 \mathrm{cGy}$. Dengan melakukan uji statistik T-Test diketahui bahwa keenam posisi TLD dilensa mata kanan dan lensa mata kiri adalah secara signifikan tidak berbeda. Dengan analisis statistik frekuensi TTest menghasilkan dosis serap yang diterima lensa mata kanan maupun lensa mata kiri adalah sebesar (3.64279 \pm 1.40286$)$ cGy per fraksi penyinaran $200 \mathrm{cGy}$.
\end{abstract}

Kata Kunci : Organ Kritis Lensa Mata, Karsinoma Nasofaring Dengan Pesawat Linac 6 MV.

\begin{abstract}
Nasopharyng cancer is a malignant that automatically has a definite border at the nasopharyng area. The closest clinical organs and are in the irradiated field are the eyes, the tolerance dose for the eye lens is $500 \mathrm{cGy}$ on TD 5/5 (complication occurred no more than $5 \%$ within 5 years). One of the methods to treat the nasopharyng is by using the $6 \mathrm{MV}$ linac teletherapy equipment and auxiliary instruments. Such as lead block. The irradiated method use is the 3 irradiated field method (2 latero-lateral field and 1 anteroposterior field). The experimen was using 14 pieces of TLDs that 3 were placed on the right and 2 placed left eye lens, each with time of irradiation using the 200 cGy fractination. By doing a statistical test of the T-Test is known that the sixth position of the $T L D$ in the right eye lens and lens left eye was not significantly different. With a statistical analysis of the frequency of T-Test produces absorbed dose received by the lens and the right eye left eye lens is at (3.64279 \pm 1.40286$)$ of irradiation $200 \mathrm{cGy}$ per fractination.
\end{abstract}

Keywords : Critical Organ of Eye's Lens, Nasopharyng cancer 6 MV Linac Teletheraphy.

\section{PENDAHULUAN}

Karsinoma Nasofaring merupakan kanker ganas yaitu pada saluran pernapasan. Di indonesia, karsinoma nasofaring menduduki tempat pertama di bidang penyakit THT. Salah satu peralatan radioterapi yang sering dipergunakan untuk penyinaran karsinoma nasofaring adalah pesawat linac. Adapun alat bantu yang sering digunakan untuk perlindungan / proteksi radiasi organ sehat mata dalam penyinaran karsinoma nasofaring adalah dengan multi leaf kolimator.

Terjadinya kerusakan jaringan organ tubuh akibat paparan radiasi pengion adalah tergantung dari sensitifitas jaringan organ itu, hal ini dapat dilihat dari masing-masing organ yang mempunyai dosis toleransi terhadap radiasi yang berbeda-beda. Lensa mata adalah salah satu organ kritis dalam penyinaran karsinoma nasofaring yang mempunyai dosis toleransi 5 Gy pada TD 5/5 yang berarti terjadi komplikasi yang tidak lebih dari $5 \%$ dalam waktu 5 tahun . TD 5/5 didefinisikan sebagai dosis toleransi minimal, yaitu dosis apabila diberikan kepada sejumlah penderita dengan metode radiasi akan mengakibatkan terjadinya komplikasi berat tidak lebih dari $5 \%$ dalam 5 tahun [2]. 
Radiasi dapat merusakkan kornea, conjunctiva, selaput pelangi dan lensa mata. Sehubungan dengan lensa mata, tempat kerusakan utama adalah pada sel pengembang biak epithelium bagian depan. Ini menyebabkan ketidaknormalan serat-serat lensa mata yang akhirnya rusak membentuk suatu bidang buram atau katarak yang menghalangi sinar untuk mencapai retina. Dosis Katarogenik terhadap lensa kira-kira sebesar 500 rad dari radiasi beta atau gamma $(\gamma)$ [8].

\section{METODE DAN BAHAN}

Jenis penelitian ini adalah jenis penelitian deskriptif kualitatif, yaitu melalui pendekatan observasi dan wawancara serta pengukuran langsung dilapangan.

\section{Alat dan Bahan Penelitian}

Alat dan bahan dalam penelitian ini terdiri dari :

- Pesawat Elekta Synergy Platform

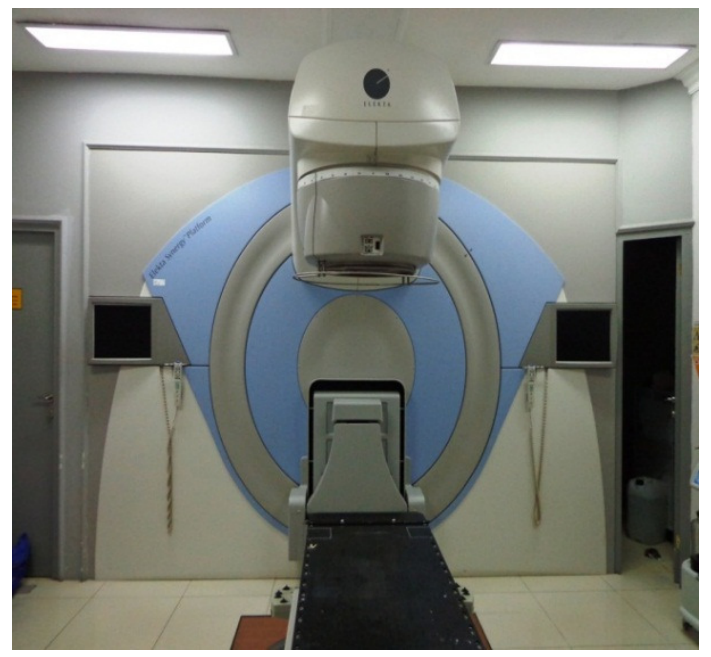

GAMBAR 1. Pesawat Elekta Synergy Platform [7].

- Termoluminisen Dosimeter TLD [8]

Alat ukur dosis serap yang dipergunakan dalam penelitian ini adalah Termoluminisen Dosimeter. Thermoluminisent dosimeter (TLD) adalah pengukuran dosis radiasi (primer / sekunder) dengan memanfaatkan pencahayaan dari bahan / material yang dipanaskan (setelah menerima radiasi).

- Pesawat Simulator

Simulator adalah alat untuk membuat simulasi penyinaran eksternal yang bertujuan untuk menentukan lokalisasi lapangan penyinaran serta menutup organ-organ yang akan dilindungi. Hasil dari simulator dijadikan pedoman untuk penyinaran dan perencanaan lebih lanjut di TPS. Pesawat Simulator yang digunakan adalah Pesawat Simulix HP.

- TLD Reader

TLD yang telah disinar radiasi, kemudian dibaca dengan menggunakan TLD Reader yang dihubungkan dengan sebuah computer dan hasil yang terbaca dapat disimpan di dalam hard disk computer atau hasil yang telah terbaca di print out.

- Nitrogen

Nitrogen ini berfungsi untuk mengurangi noice pada bacaan TLD.

- Furnace

TLD yang telah dibaca lalu dipanaskan, bertujuan untuk membersihkan dari respon radiasi latar agar semua elektron yang berada di dalam bahan TLD berada dalam 
keadaan awal dan tidak menyimpan respon radiasi sama sekali. TLD yang dipanaskan menggunakan furnace pada suhu $400^{\circ} \mathrm{C}$ selama $1 \mathrm{jam}$.

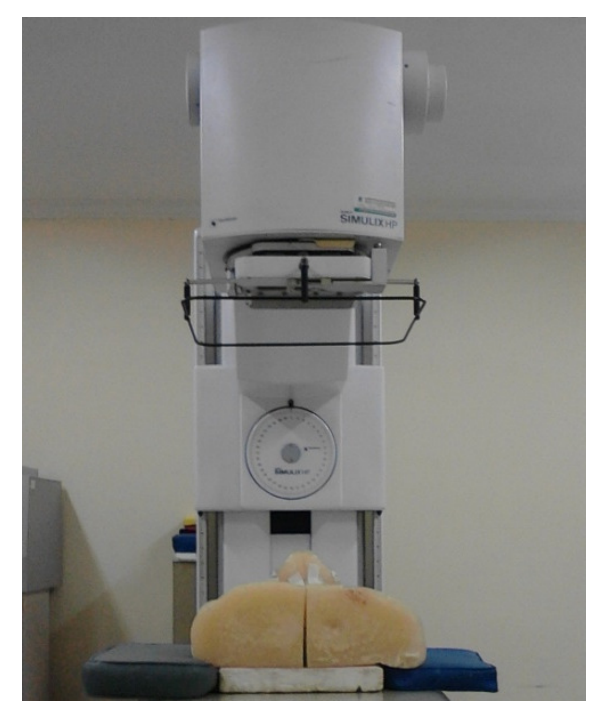

GAMBAR 2. Pesawat Simulix HP [RSUPN Dr. Cipto Mangunkusumo]

- Oven

Setelah TLD tersebut dipanaskan dengan furnace selama 1 jam, kemudian TLD tersebut kembali dipanaskan dalam Oven pada suhu $200^{\circ} \mathrm{C}$ selama 2 jam.

Di bidang radioterapi, lilin/paraffin sudah sering digunakan sebagai alat bantu dalam penyinaran terutama sebagai bahan untuk menghomogenkan foton sinar-X atau sinar gamma yang akan mengenai objek yang tidak rata sehingga dosis radiasi yang diberikan juga dapat homogen. Oleh karena itu fantom lilin dipakai dalam penelitian ini sebagai pengganti objek yang akan disinar dan akan dapat dilakukan simulasi untuk mengukur dosis serap pada organ kritis lensa mata sehingga akan diketahui apakah dosis serap yang diterima organ kritis tersebut masih dalam batas toleransi ataukah sudah melebihi. Gambar 3, adalah fantom kepala dengan peletakan TLD pada kedua mata.

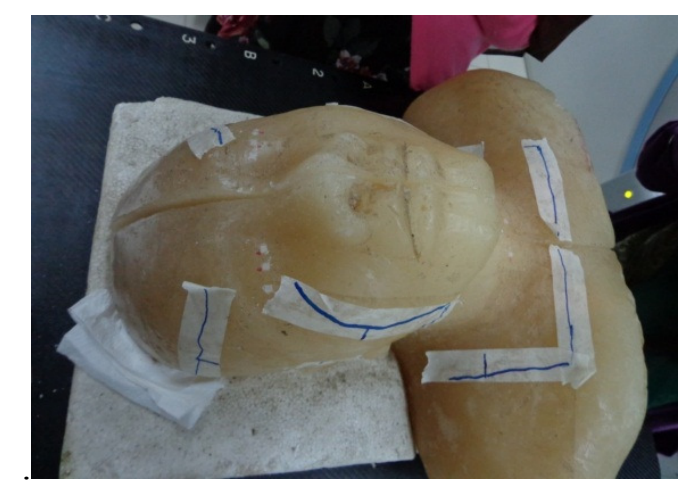

GAMBAR 3. Fantom kepala dengan TLD pada kedua mata.

Dari hasil baca TLD didapat data terhadap masing-masing TLD yang sudah dikelompokkan menjadi 7 TLD pada mata kanan 7 TLD pada mata kiri per fraksi penyinaran 200 cGy. Keseluruhan data diolah dengan menggunakan analisa statistik. Data out put analisa statistik tersebut dikalikan 25 untuk mencapai dosis penyinaran $500 \mathrm{cGy}$. Hasil akhir perkalian ini kemudian dibandingkan dengan dosis toleransi untuk mengetahui apakah dosis serap mata kanan dan kiri berada di bawah atau di atas dosis toleransi.

Dari hasil penelitian diatas, diperoleh beberapa persamaan :

- Untuk menghitung dosis Serap dinyatakan dalam persamaan 1 dibawah ini [6]. 


$$
D=\frac{d E}{d m}
$$

- Untuk menghitung pemberian dosis dinyatakan dalam persamaan (2) dibawah ini.

$$
M U=\frac{\text { Dosis Tumor }}{\text { PDD x Out Factor }(S c x S p) \times \text { Factor Koreksi }}
$$

- Untuk menghitung Hasil Netto TLD $(\bar{x})$

$$
\operatorname{TLD}(\bar{x})=\text { hasil kalibrasi }- \text { backgroung }
$$

- Untuk menghitungFK dinyatakan dalam persamaan (5)

$$
\mathrm{FK}=\frac{\text { Dosis Serap Per Fraksinasi }}{\text { Hasil Netto }}
$$

Untuk menentukan uji Statistik tendensi sentral dilakukan berdasarkan :

$$
\begin{aligned}
& \text { Rata-rata / Mean : } \\
& \overline{\mathrm{x}}=\frac{\sum \mathrm{x}}{\mathrm{n}}
\end{aligned}
$$

Standar Deviasi / SD

$$
S D=\frac{\sum\left(x_{i}-x\right)^{2}}{n}
$$

Varian

$$
\text { Varian }=\sum \frac{\left(x_{i}-x\right)^{2}}{n}
$$

Uji T-Test dilakukan berdasarkan : Uji t untuk varian yang sama (equal variance) menggunakan rumus dalam persamaan (8).

$$
\mathrm{T}=\frac{\overline{\mathrm{x}}_{1}-\overline{\mathrm{x}}_{2}}{\mathrm{St} \sqrt{\left(\frac{1}{\mathrm{n}_{1}}+\frac{1}{\mathrm{n}_{2}}\right)}}
$$

$\operatorname{dimana} \mathrm{S}_{\mathrm{t}}^{2}=\left(\mathrm{n}_{1}-1\right) \mathrm{S}_{1}{ }^{2}+\left(\mathrm{n}_{2}-1\right)=\frac{\mathrm{s}_{2}{ }^{2}}{\mathrm{n}_{1}-\mathrm{n}_{2}-2}$

dan $\mathrm{df}=\mathrm{n}_{1}-\mathrm{n}_{2}-2$

Keterangan :

$\mathrm{n}_{1}$ atau $\mathrm{n}_{2}=$ jumlah sampel kelompok 1 atau 2

$\mathrm{S}_{1}$ atau $\mathrm{S}_{2}=$ standar deviasi sampel kelompok 1 atau 2

\section{HASIL DAN PEMBAHASAN}

Hasil perhitungan dosis serap pada lensa mata kanan per fraksi pada masing-masing TLD kanan seperti pada tabel 1 .

TABEL 1. Dosis serap per fraksi penyinaran pada lensa mata kanan

\begin{tabular}{|c|c|c|c|}
\hline No. TLD & Faktor Koreksi $\left(\frac{\mathrm{cGy}}{\mu \mathrm{C}}\right)$ & Penelitian $(\mu \mathbf{C})$ & Dosis Serap (cGy) \\
\hline 1 & 47,29 & 1,021 & 48,28 \\
\hline 2 & 49,05 & 0,949 & 46,54 \\
\hline 3 & 49,80 & 0,891 & 44,37 \\
\hline 4 & 48,02 & 1,116 & 53,59 \\
\hline 5 & 46,13 & 1,011 & 46,63 \\
\hline 6 & 44,92 & 1,037 & 46,58 \\
\hline 7 & 45,59 & 1,021 & 46,54 \\
\hline
\end{tabular}


Hasil perhitungan dosis serap pada lensa mata kiri per fraksinasi pada masing-masing TLD adalah seperti pada tabel 2 .

TABEL 2. Dosis serap per fraksi penyinaran pada lensa mata kiri

\begin{tabular}{|c|c|c|c|}
\hline No. TLD & $\begin{array}{c}\text { Faktor Koreksi } \\
\left(\frac{\mathrm{cGy}}{\mu \mathrm{C}}\right)\end{array}$ & Penelitian $(\mu \mathrm{C})$ & Dosis Serap (cGy) \\
\hline 1 & 49,69 & 0,856 & 42,53 \\
\hline 2 & 48,13 & 0,981 & 47,21 \\
\hline 3 & 46,38 & 0,987 & 45,77 \\
\hline 4 & 48,56 & 0,996 & 48,36 \\
\hline 5 & 46,28 & 1,017 & 47,06 \\
\hline 6 & 48,77 & 1,014 & 49,45 \\
\hline 7 & 45,96 & 0,913 & 41,96 \\
\hline
\end{tabular}

Kesetaraan posisi adalah pengujian hasil penelitian dosis serap dari TLD yang diletakkan pada 7 titik di lensa mata kanan dan 7 titik di lensa mata kiri. Pengujian kesetaraan posisi dilakukan untuk mengetahui apakah TLD yang diletakkan pada 6 titik tersebut mempunyai variansi dan rata-rata (mean) yang sama / identik ataukah tidak. Pengujian yang dilakukan terhadap masingmasing sampel posisi TLD akan memberikan hasil variansi. Variansi yang demikian disebut dengan variansi hasil pengujian atau variansi dalam sampel (within sampel varation) posisi TLD. Jika rata-rata masing-masing sampel posisi TLD dirata-ratakan lagi maka dapat ditentukan variansi yang disebut antar sample (between sampel varation) posisi TLD. Perbandingan dalam sampel inilah yang akan dipakai untuk komparasi dari 3 posisi TLD.

Oleh karena $\mathrm{F}_{\text {hitung }}$ terletak pada daerah $\mathrm{H}_{0}$ diterima $\left(\mathrm{F}_{\text {hitung }}<\mathrm{F}_{\text {tabel }}\right) 0.348>1.019$ maka dapat disimpulkan rata-rata keenam titik posisi TLD tersebut secara signifikan tidak berbeda. Dengan demikian rata-rata hasil penelitian dosis serap dengan menggunakan TLD pada sisi kanan mata kanan, sisi bagian tengah mata kanan, sisi bagian kiri mata kanan, bagian sisi kanan mata kiri, bagian tengah mata kiri dan bagian sisi kiri mata kiri adalah sama. Dengan kondisi tersebut berarti masing-masing TLD dapat diasumsikan bahwa satu TLD mewakili satu kali pengukuran, sehingga untuk mengetahui dosis serap pada mata dapat dilanjutkan dengan analisa statistik frekuensi untuk menghitung rata-rata (mean) dan standar deviasi keseluruhan dosis serap pada lensa mata per fraksinasi penyinaran (200 cGy).

Setelah rata-rata data keseluruhan (14 data) diketahui identik, maka dapat dicari juga rata-rata dan standar deviasi dosis serap lensa mata per fraksi dengan menggunakan analisis statistik frekuensi ( diolah dengan program T-Test ) dan menghasilkan data seperti yang tercantum pada tabel 4.5 Pada terapi karsinoma nasofaring dilakukan treatment planning system yang bertujuan untuk merencanakan pemberian dosis yang akan diterima pasien pada daerah target volume maupun organ kritis yang ada disekitarnya. Jika terdapat adanya benjolan dan tidak sama besarnya pada kedua kelenjar tyroid maka dibuat TPS dengan dosis perbandingan, misalnya 1 : 2. Akan tetapi, jika ingin dibuat 2 TPS dengan lapangan yang sama antara kiri dan kanan maka diberikan dengan dosis yang sama. Untuk 3D pembuatan TPS dilakukan satu kali planning yaiu dengan posisi lateral kanan, lateral kiri dan AP.

\section{KESIMPULAN}

Dari hasil penelitian dapat disimpukan bahwa lensa mata adalah organ kritis yang harus dilindungi selama penyinaran karsinoma nasofaring, karena termasuk dalam lapangan penyinaran, meskipun tidak tersinar karena diberi perisai radiasi. Dosis toleransi yang diterima lensa mata adalah sebesar 500 cGy pada TD 5/5 (peluang komplikasi tidak lebih dari $5 \%$ dalam waktu 5 tahun). Hasil penelitian dengan analisa statistik uji T-Test dapat diambil kesimpulan bahwa dosis serap yang diterima lensa mata (baik mata kanan maupun mata kiri) adalah sebesar 
$3.64279 \pm 1.40286$ cGy per fraksinasi penyinaran 200 cGy. Dengan uji statistik T-Test diketahui bahwa dosis serap yang terbaca dari TLD berdasarkan 6 posisi ( sisi kanan mata kanan, sisi tengah mata kanan, sisi kiri mata kanan, sisi kanan mata kiri, sisi tengah mata kiri dan sisi kiri mata kiri) adalah sama/identik. $\mathrm{H}_{0} \mathrm{~F}_{\text {hitung }}<\mathrm{F}_{\text {tabel }}(0.348>1.019)$ diterima, karena tidak ada perbedaan yang signifikan antara dosis pada serap lensa mata kanan dengan dosis serap pada lensa mata kiri. Hasil penelitian, dengan analisa statistik dengan uji T-Test diperoleh nilai $\mathrm{t}=1,019$ dan $\mathrm{p}$ value $=0,348$ dengan tingkat kesalahan (alpha) $5 \%$ diketahui nilai $\mathrm{p}$ value $>$ 0,05 . karena dari hasil penelitian yang diperoleh, dosis serap yang diterima lensa mata kanan dan lensa mata kiri tidak melebihi dari batas normal.

\section{DAFTAR PUSTAKA}

[1] Argadikoesoema,S, 1998, Faktor Prediksi Respon Radiasi Pada Karsinoma Nasofaring, Disertai, UI Jakarta

[2] Herawati, Sri dr \& Rukmini,Sri dr, 2002, Ilmu Penyakit Telinga Hidung Tenggorok, Buku Kedokteran EGC, Jakarta.

[3] J.Hall,Eric, 2000, Radibiology for the Radiologist. fifth editio, Philadelphia, WB Saunders.

[4] Suyatno. 2010, Bedah Onkologi Diagnostik dan Terapi, Sagung Seto, Jakarta.

[5] Pearce,E, 2011, Anatomi dan Fisiologi untuk paramedis, PT. Gramedia, Jakarta.

[6] Akhadi, Mukhlis Drs, 2000, Dasar-dasar Proteksi Radiasi, PT. Rineka Cipta, Jakarta.

[7] RSUPN Dr. Cipto Mangunkusumo, 2001, Standar Prosedur Penanganan Karsinoma Nasofaring, Jakarta.

[8] Cember, Herman, 2011, Pengantar Fisika Kesehatan. Edisi Kedua.Pergamon Press Inc, New York, USA.

[9] Khan, FM, 1994, The Physics of Radiation Therapy, second edition, University Hospitals, Baltimore, USA.

[10] Prawihartomo, S \& Sutarmi, S, 1990, Anatomi dan Faal Tubuh, Edisi ke Tiga, Erlangga, Jakarta

[11] Vogel, 1973 dalam Susworo, 1990, Kombinasi Radiasi Eksterna dan Intrakaviter (Alternatif Pengobatan Karsinoma Nasofaring yang Responsive terhadap Radiasi), Disertai, UI Jakarta

[12] http://canasofaring.blogspot.com/2013/01/ca-nasofaring.html, 23 Januari 2013, di akses 25 mei 2014. 